\title{
Relation between night visit rates and deprivation measures in one general practice
}

\author{
R D Carlisle, S P Johnstone, J C G Pearson
}

\begin{abstract}
Objective-To compare night visit rates in different electoral wards of one general practice with the Jarman and Townsend deprivation scores and unemployment rates.
\end{abstract}

Design-Analysis of computerised workload data.

Setting-General practice in centre of Mansfield, Nottinghamshire.

Outcome measure-Visits made in 588 nights to the 11998 patients on the practice list.

Results-Night visit rates in 15 electoral wards varied from 19.6 to 55.3 visits per 1000 patients per year. The rates showed a significant association with the Townsend score $(p=0.004)$ and the unemployment rate $(p=0.03)$ but not with the Jarman score $(p=0 \cdot 3)$. The Townsend score explained $49 \%$ of the variability; unemployment explained $31 \%$ and the Jarman score explained $9 \%$.

Conclusions-Even in a general practice not eligible for deprivation payments there was a $2 \cdot 8$-fold variation in night visit rates between wards. In this practice the Townsend score was significantly better at predicting night visit rates than the Jarman score. This method of looking at internal variation in workloads in computerised practices could give more direct data on the relation between deprivation and general practice workload than has previously been available.

\section{Introduction}

Wide variations in night visit rates between general practices, ranging from 1.2 to $46 \cdot 1$ visits per 1000 patients per year, have been reported. ${ }^{1}$ Individual practices in deprived areas have reported high night visit rates, but practices in much less deprived areas have reported rates still higher. ${ }^{23} \mathrm{~A}$ single health centre in Inverclyde reported a substantial variation in rates between practices serving the same catchment area, ${ }^{4}$ and in a study of night visit claim forms in Nottinghamshire only $1 \%$ of the observed variability could be explained by the area of the practice. ${ }^{1}$ It seems that the way practices look after their patients, both during the day and at night, is a more powerful determinant of night visit rates than inherent differences between populations. ${ }^{5}$

In 1990 the new general practitioners' contract incorporated deprivation payments. ${ }^{6}$ Practices with patients living in wards with a Jarman score of more than 30 receive an additional capitation based payment. There has been considerable debate on this system, both with regard to how it operates in detail ${ }^{8}$ and on how well the Jarman score correlates with other morbidity and mortality measures, ${ }^{9-12}$ but little direct information exists on the effect of deprivation on general practice workload. ${ }^{13} 14$

This study describes the variation in night visits carried out in different electoral wards by general practitioners from one practice and analyses how much of this deprivation can be predicted by the three deprivation measures most readily available: the Jarman score, ${ }^{15}$ the Townsend score, ${ }^{16}$ and the unemployment rate. ${ }^{12}$ This should give a more direct way of studying the effects of deprivation on this aspect of general practice workload.

\section{Method}

The practice is a six partner, town centre practice in Mansfield. In September 1991 the list size was 11998. The patients are distributed over a total of 29 electoral wards but the study was confined to the 15 wards in which the practice has more than 250 patients. Unemployment in Mansfield is $11.7 \%$, which is close to the national average of $11.0 \%$. The Jarman scores of the wards studied range from -25.3 to 29.0 (national average 0 ).

On call is carried out by five of the partners and a trainee in an equal rota with no use of a deputising service. Night visits were defined as in the 1990 contract-that is, a visit requested and performed between the hours of 2200 and 0800 . The age, sex, and postcode of every patient visited between 20 August 1990 and 25 April 1992 was extracted from the practice's computer. An electoral ward was assigned to each postcode with the software package PCCAMM (Claymore Services, Exeter). The practice population for each ward was obtained from the family health services authority's database; 11549 of the practice's 11998 patients could be assigned wards.

The annual report of the director of public health for Central Nottinghamshire Health Authority was the source of the Jarman and Townsend deprivation scores and the total ward populations in the 1981 census. The deprivation scores are calculated from census variables according to a predetermined weighting (see table IV) and are updated only every 10 years. Unemployment figures were available from the Nottinghamshire County Council for January 1992.

\section{Results}

In the 588 nights studied, general practitioners from the practice made 668 visits. The total from April 1991 to April 1992 was 398, giving an annual rate of 33.2 visits per 1000 patients. A total of 149 visits $(25 \%)$ were to children under 5 years, who make up $6.6 \%$ of the practice list ( 803 patients), and 131 visits (22\%) were to people aged over 64 , who make up $12.6 \%$ of the practice list (1537 patients).

Table I shows the number of night visits carried out in the 15 wards studied. The calculated annual night visit rates varied between 19.6 and 55.3 per 1000 patients.

The ability of the three measures of deprivationJarman score, Townsend score, and unemployment

Medical Centre,

J C G Pearson, dean of studies

$B M \mathcal{F} 1993 ; 306: 1383-5$ 
rate- to predict the night visit rates for the wards was investigated by using linear regression (figure). The Townsend score $(p=0.004)$ and the unemployment rate $(p=0.03)$ both were significantly associated with the night visit rate, explaining $49 \%$ and $31 \%$, respectively, of the variability between wards. The Jarman score, explaining only $9 \%$ of the variability, did not show a significant degree of association $(p=0 \cdot 3)$.

The relation between the scores and night visit rates was further investigated by using multiple regression (table II). The Townsend score and the unemployment rate were each able to add to the percentage of the variability explained by the Jarman score alone $(49 \%$ and $24 \%$, respectively). Neither the Jarman score nor the unemployment rate were able to add substantially to the amount explained by the Townsend score. The Jarman score could not add to the amount explained by

TABLE I-Night visit rates, farman and Townsend scores, and unemployment rate in electoral wards in one general practice

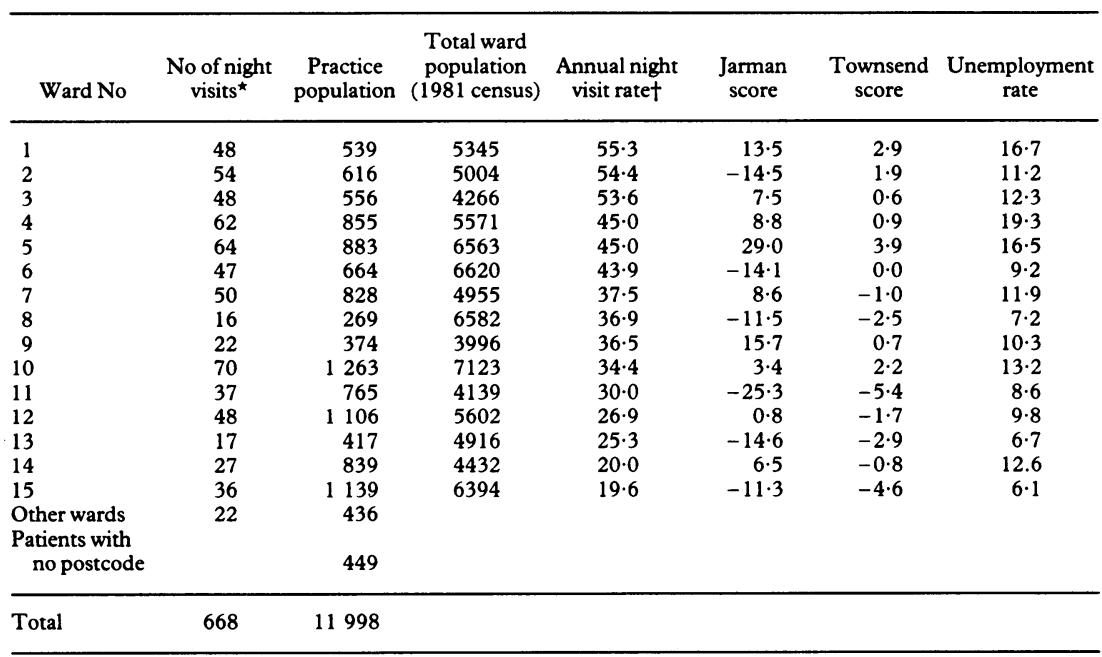

*558 Day period. $\quad$ †Number of night visits $\times 365 / 558$ per 1000 patients.

TABLE II-Percentage of the variability between wards in night visit rate explained by farman score, Townsend score, and unemployment rate in 1992, showing additional amount that could be explained by adding one variable to regression equation

\begin{tabular}{|c|c|c|c|c|c|}
\hline Basic variable & \% Explained & $\mathrm{p}$ Value & Added variable & $\%$ Added & $\mathrm{p}$ Value \\
\hline Jarman score & $9 \cdot 0$ & 0.3 & $\begin{array}{l}\text { Townsend score } \\
\text { Unemployment rate }\end{array}$ & $\begin{array}{l}49 \cdot 4 \\
24 \cdot 4\end{array}$ & $\begin{array}{l}0.003 \\
0.06\end{array}$ \\
\hline Townsend score & $49 \cdot 2$ & 0.004 & $\begin{array}{l}\text { Unemployment rate } \\
\text { Jarman score }\end{array}$ & $\begin{array}{l}0 \cdot 1 \\
9 \cdot 2\end{array}$ & $\begin{array}{l}0 \cdot 9 \\
0 \cdot 1\end{array}$ \\
\hline $\begin{array}{l}\text { Unemployment rate } \\
\text { (1992) }\end{array}$ & $31 \cdot 1$ & 0.03 & $\begin{array}{l}\text { Townsend score } \\
\text { Jarman score }\end{array}$ & $\begin{array}{r}18 \cdot 2 \\
2 \cdot 3\end{array}$ & $\begin{array}{l}0.06 \\
0.5\end{array}$ \\
\hline
\end{tabular}

unemployment rate, but the Townsend score was able to explain an additional $18 \%$ of the variability. Thus, of the three variables investigated, the Townsend score was significantly better at predicting night visit rate than the Jarman score $(p=0.003)$ and almost reached significance with regard to unemployment rate $(p=0.06)$. The unemployment rate was better than the Jarman score, and this difference was also on the borderline of significance $(p=0 \cdot 06)$.

TABLE IV-Percentage of variability between wards in night visit rate explained by the component variables of the farman and Townsend indices

\begin{tabular}{lcccc}
\hline \multicolumn{1}{c}{ Census variable } & $\begin{array}{c}\text { Townsend } \\
\text { weighting }\end{array}$ & $\begin{array}{c}\text { Jarman } \\
\text { weighting }\end{array}$ & $\begin{array}{c}\text { \% Of variability } \\
\text { explained }\end{array}$ & p Value \\
\hline No car & 1.0 & & 44.4 & 0.007 \\
Non-owner occupier & 1.0 & & 40.5 & 0.01 \\
Overcrowding & 1.0 & 2.9 & 40.1 & 0.01 \\
Unemployment (1981) & 1.0 & 3.34 & 33.9 & 0.02 \\
Children under 5 & & 4.64 & 0.1 & 0.9 \\
Single parent & & 3.01 & 3.7 & 0.5 \\
Moved within year & & 2.68 & 4.9 & 0.4 \\
Unskilled & 3.74 & 7.4 & 0.3 \\
Pensioners living alone & & 6.62 & 0.0 & 0.9 \\
Ethnicity & & 2.5 & $10.9+$ & 0.2 \\
\hline
\end{tabular}

${ }^{\star}$ For description of census variables see table III

†Negative association (high ethnicity associated with low night visit rate).

Table III shows the component variables used to calculate the Jarman and Townsend scores for the wards studied. The relation of the night visit rate to these variables was also investigated by using linear regression (table IV). Each of the four variables used in the Townsend score showed a significant degree of association with night visit rate. Only two of the eight variables used in the Jarman score, those that are common to the two scores, showed a significant degree of association. The Jarman score gives most weight to the variables that showed no association, and the ethnic variable was negatively associated, thus diluting the effect of the two variables that were significantly associated.

\section{Discussion}

Previous studies used the narrower definition (in the old contract) of night visits from 2300 to 0700 . With this in mind, our overall rate is probably in the middle of the range of those previously reported. The practice's unemployment rate and deprivation indices are close to the national average, but as in many town centre practices this hides a considerable variability in the

*No car=percentage of households without access to a car; non-owner occupier=percentage of homes not occupied by owner; overcrowding=percentage of residents living in households of more than one person per room; unemployment=percentage of economically active residents whom are unemployed (Jarman included temporarily sick people); children under $5=$ children under 5 as a proportion of all residents in private households; single parent $=$ people in households of one person over 16 and one or more child under 16 as a proportion of all residents in private households; moved within year=people aged 1 or over with a usual address one year before the census different from present usual address; unskilled=percentage of people in households headed by a person in socioeconomic group V; pensioners living alone=pensioners as a proportion of all residents in private households; ethnicity=people in households headed by a person born in the New Commonwealth or Pakistan as a proportion of all residents in private households. 

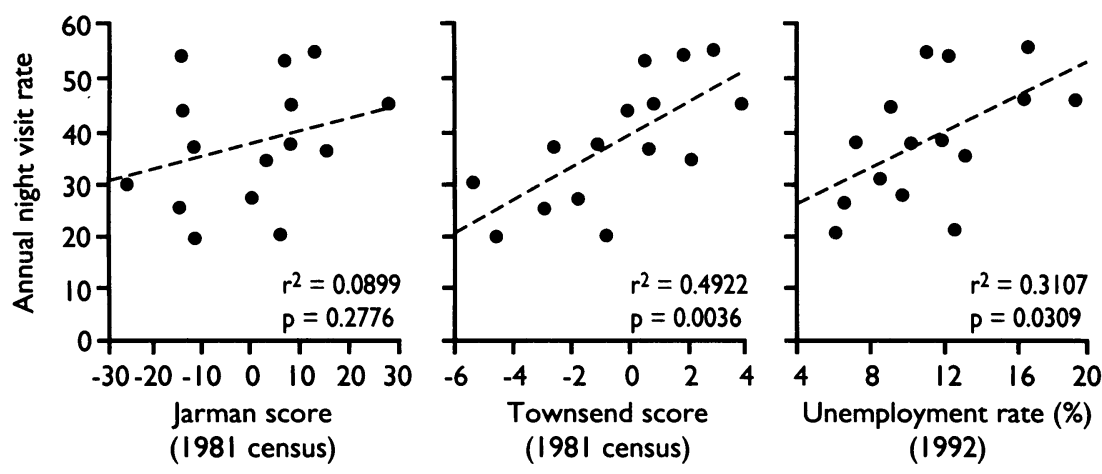

Relation between calculated annual night visit rate and measures of deprivation

degree of deprivation between different parts of the practice area.

The data reported are likely to be accurate because there is a financial incentive to record them, and the numbers compare closely with payments received from the family health services authority. The validity of the conclusions depends on the practice's patients in each ward being comparable to the general population. For this reason the study was confined to those wards having at least 250 of the practice's patients.

The study showed a $2 \cdot 8$-fold variation in night visit rate between wards. Because the patients are looked after by the same doctors all the time this is likely to represent a true difference in patient demand for night visits. If the Townsend score is used as a measure of deprivation a significant proportion of this variability can be explained. This supports the suggestion that deprivation payments could be extended to practices with less extreme degrees of deprivation, ${ }^{17}$ for example by means of a capitation system weighted for deprivation that does not include an abrupt cut off point.

It is interesting that we found no significant association with the Jarman index. This index was derived by general practitioners choosing variables they felt created workload pressure ${ }^{15}$; however, only two of these eight component variables were related to night visits in our practice. It may be that some factors given a high weighting-for example, pensioners living alone-are relevant to other aspects of workload. Other factors-for example, ethnicity, which was negatively associated-may not be relevant in this particular practice, which has a low proportion of patients of non-British origin in all wards. It is striking, however, that there was no association with factors such as children under 5 years. A quarter of all night visits were to children under 5 , and there is nearly a twofold difference between different wards in the prevalence of under $5 \mathrm{~s}$. The type of ward children come from seems to be more important than the number of children in the ward.

In his original paper Jarman pointed out the difficulties in validating his scores with direct workload measures such as visit rates, because visit rates depend on service provision as well as patient demand. We believe that our method of looking at internal variations within a practice is a means of getting around this problem. If more practices were to report their internal variations in consultation and visit rates it would be possible to determine directly which score best reflects the effect of deprivation on general practice workload and provides a means of quantifying that effect.

1 Sheldon MG, Harris SJ. Use of deputising services and night visit rates in general practice. $B M \mathcal{F}$ 1984;289:474-6.

2 Livingstone AE, Jewell JA, Robson J. Twenty four hour care in inner cities: two years' out of hours workload in east London general practice. $B M \mathcal{J}$ 1989;299:368-70.

3 Pitts J, Whitby M. Out of hours workload of a suburban practice: deprivation or expectation. $B M 7$ 1990;300:1113-5.

4 Usherwood TP, Kapasi MA, Barber JH. Wide variations in the night visiting rate. $7 R$ Coll Gen Pract 1985;35:395.

5 Buxton MJ, Klein RE, Sayers J. Variations in GP night visiting rates: medical organisation and consumer demand. $B M \mathcal{F}^{1977}$; ;:827-30.

6 Department of Health. General practice in the National Health Service: the 1990 contract. London: HMSO, 1989.

7 Smith GD. Second thoughts on the Jarman index. BMY 1991;302:359-60.

8 Carr-Hill RA, Sheldon T. Designing a deprivation payment for general practitioners: the UPA(8) wonderland. BMF 1991;302:393-6.

9 Charlton JRH, Lakhani A. Is the Jarman underprivileged area score valid? $B M 7$ 1985;290:1714-6.

10 Carstairs V, Morris R. Deprivation mortality and resource allocation. Community Medicine 1989;11:364-72.

11 Mays N, Chin S. Relation between all cause standardised mortality ratios and two indices of deprivation at regional and district level in England. two indices of deprivation at regional

12 Campbell DA, Radford JMC, Burton P. Unemployment rates: an alternative to the Jarman index? $B M{ }^{7} 1991 ; 303: 750-5$.

13 Leavy R, Wood J. Does the underprivileged area index work? $B M Y$ 1985;291:709-11.

14 Curtis SE. Use of survey data and small area statistics to assess the link between individual morbidity and neighbourhood deprivation. $\mathcal{I}$ Epidemiol Community Health 1990;44:62-8.

15 Jarman B. Identification of underprivileged areas. BMF 1983;286:1705-9.

16 Townsend P, Phillimore P, Beattie A. Inequalities in health in the nonhern region: an interim report. Bristol: Northern Regional Health Authority, 1986. 17 Senior ML. The Jarman index. BMf 1991;302:661.

(Accepted 23 March 1993)
We had occasion in the British Medical Journal of December 9th to comment severely on an antivivisectionist address recently delivered in Nottingham by the Bishop of Southwell, in which that prelate made a most unworthy attack not only on physiologists, but on "the profession" of "English doctors," to use his own words. As might be expected such an address has given birth to a series of misstatements in the Nottingham press. Among others our attention has been drawn to a statement purporting to be an account of the action by the British Medical Association on July 29th, 1892, when the following resolution was unanimously passed: "That this general meeting of the British Medical Association records its opinion that the results of experiments on living animals have been of inestimable service to man and to the lower animals and that the continuance and extension of such investigations is essential to the progress of knowledge, the relief of suffering, and the saving of life." The important general meeting at which this was passed is described in one communication as a "few gentlemen" only "chance visitors," and in another as a few "festive medico snatching time between conviviality and sight seeing," while the fact of the resolution being passed unanimously is explained away by the allegation that the "motion was brought forward without the usual notice." As our readers are well aware the resolution in question was advertised beforehand in the Daily Journal according to custom, and it was moved in a large general meeting of the Association (vide Nottingham Daily Guardian, July 30th, 1892) attended not only by the general body of members but also by the members of the Council who represent each Branch of the Association. The Bishop's example of lack of truth and candour has evidently not been thrown away on his followers. We can only repeat our regret that a high dignitary of the Church should serve not only as a promoter, but also as an instigator, of tactics so disingenuous as to require to be bolstered up by misstatements and distortions of well-known and easily verified facts.

(BMF 1893;ii:1396.) 